\title{
¿Teología de la liberación en el post-socialismo?*
}

\author{
Rolando Alvarado S. J., \\ Centro de Reflexión Teológica, \\ San Salvador.
}

\section{El cuestionamiento de la "teología de la liberación"}

Formulo a modo de pregunta el título que encabeza estas páginas. No es un recurso literario para llamar la atención. Soy consciente que al hacerla asumo la inquietud que flota en algunos ambientes en torno al presente y futuro del movimiento teológico internamente plural, que, surgido en Latinoamérica a finales de los años sesenta y extendido a otros continentes, se conoce como teologla de la liberación. Desde los acontecimientos de 1989, se hace presente de una u otra manera esa inquietud. No debería extrañarnos la pregunta, pues la teología de la liberación se presentó a sí misma desde sus inicios como una teología preocupada por mostrar la relevancia del mensaje cristiano para la situación sociocultural de sus destinatarios. Quiso no ser un discurso intemporal, ajeno a los acontecimientos, que condicionan la recepción y el cumplimiento del mensaje de Jesucristo.

Es innegable que los acontecimientos de finales de los ochenta han perfilado una nueva figura sociocultural de la cual suelen señalarse múltiples elementos que tan sólo mencionamos: globalización de la economía, acrecentamiento y extensión de la miseria, reconocimiento defensivo de las peculiaridades culturales, incremento de la comunicación masiva $\mathrm{c}$ informática, predominio de lo científico-técnico, estimación de nuevos valores, resurgir un tanto agresivo y

: Este artícula fue escrito con ocasión de las "Segundas jornadas de teología", celebradas en Madrid, del 28 al 30 de noviembre de 1997, por la Asociación de Europa de Teología Católica. Con anterioridad fue publicado en M. Rubio (ed.), Cristianismo español posiconciliar (perfiles y tareas), Madrid, 1998, pp. 139-159. 
difuso del fenómeno religioso, etc. Son tales los cambios que se están produciendo desde entonces que algunos analistas hablan de un "cambio de época"1 más que de una época de cambios.

El cambio de época al cual estamos asistiendo ha lanzado a la fe crisliana nuevos desafíos y ha puesto en crisis a la teología, según nos dice el cardenal Razinger2. La teología de la liberación, como era de esperar, dada la importancia que olorga metodológicamente a la siluación a la que se dirige el mensaje creyente, participa de esa crisis. Para clla, scgún G. Gutiérrez, se ha cerrado prácticamente un ciclo y se ha abierto otro:

Una serie de acontecimientos económicos, políticos y eclesiales, tanto de orden mundial como latinoamericano y nacional, hacen pensar que está concluyendo la etapa en la que nació y caminó la reflexión teológica recordada páginas atrás. Los años pasados fueron estimulantes y creativos por una parte, tensos y conflictivos por otra. Ante las nuevas situaciones (el agravamiento de la pobreza y la pérdida de vigencia de ciertos proyectos políticos, por ejemplo), muchas de las discusiones anteriores no responden a los retos acluales. Todo parecería indicar que un periodo distinto comienza3.

La divergencia surge en el momento de valorar la crisis que supone adentrarse en una nueva elapa e intentar predecir hacia dónde se orienta: si estamos asistiendo a la desaparición de la teología de la liberación o a su revitalización. Voy a tomar postura, no sin antes decir que, a la luz de la fe y el caminar de la Iglesia, conviene relativizar el que una determinada teología entre en crisis. Lo importante no es la duración o pervivencia de una teología, sino la realidad y actualidad de la revelación y de la fe que esa teología intenta comprender y lormular. En ese sentido, me parece lúcido lo que, en otro momento, dice el mismo Gutiérrez: "Más deben interesarnos los sufrimientos y las angustias, las alegrías y las esperanzas de las personas de hoy, así como la siluación actual de la tarea evangelizadora de la Iglesia, que el presente y el futuro de una determinada teología"4.

Sin embargo, y supuesta esa relativización, no carece de validez e importancia el que se indague sobre la vigencia de una determinada comprensión teológica. Y esto por varias razones. El "dar razón de la esperanza" (1 Pe 3,15) no sólo responde al irrenunciable ejercicio de la racionalidad, por parte de los hombres, y al permanente análisis crítico sobre la configuración alcanzada, a la

1. X. Gorostiaga, "La mediación de las ciencias sociales y los cambios intemacionales", en Combio social y pensamiento cristiano, Trotta, Madrid, 1993, pp. 123-144.

2. Cfr. J. Ratzinger, "Situación actual de la fe y la teología Il", Ecclesia 2829 (1997), p. 9.

3. G. Gutiérrez, "La teología: una función eclesial", Póginas XIX/130, 1994, P. 15.

4. G. Gutiérrez, "Una teología de la liberación en è contexto del tercer milenio", en El futuro de la reflexión reológica en América Latina", Documentos del CELAM No.141, Colombia, 1997, p.104. 
vez limitante y potenciadora, de dicho ejercicio, en un momento de la historia y en una particular tradición sociocultural, sino que, ante todo, se pretende dar cuenta teórica de manera significaliva de esa esperanza por demanda interna de la propia fe. Los creyentes sabemos que toda elaboración teológica debe estar abierta a la novedad de la revelación de Dios a fin de facilitar y profundizar la respuesta de fe a dicha revelación. Si una explicación teológica se evidencia incapacitada para percibir esa novedad y potenciar esa respuesta, bien está que se modifique periférica o sustancialmente, o que incluso llegue a desaparecer.

Sería absurdo querer aferrarse a la permanencia de cualquier teología. Y no sólo absurdo. Se puede correr el peligro de hacer de esa teología una especie de ídolo. A la teología de la liberación, tan atenta desde siempre a desenmascarar los mecanismos idolátricos y denunciar los diversos tipos de idolatría, no le resulta extraño el que, llegado el momento, tenga que pertenecer al pasado. Lo que sí le llama poderosamente la atención es la precipitación y quizá, alivio interesado, con que en algunos ámbitos extra e intraeclesiales se ha declarado su muerte. ¿Qué subyace en la declaración del fallecimiento de la teología de la liberación y el vaticinar su paulatina desaparición? ¿Por qué el empeño en enviarla al "sótano de los muertos del occidenle?"'s. Lo mínimo que puede decirse es que a lo mejor se está menospreciando la manera que han encontrado algunas iglesias para dar cuenta de y argumentar su esperanza, e incluso se pueda estar desperdiciando lo que de perenne y enriquecedor pueda haber como aporte a la Iglesia universal, por parte de esas iglesias, a través del discurso teológico que han elaborado.

No retrasemos más el asunto y retomemos la pregunta inicial: ¡cuál es el estado actual y las perspectivas de futuro de la teología de la liberación? Imposible responder aquí a esta pregunta dando una visión de conjunto con un mínimo de suficiencia y rigor. Existen espléndidos estudios y varios artículos que cubren esta deficiencia y a los que animo a acudiŕ. La impresión general que suscitan es

5. Cfr. F. Hinkelammert, "La metafísica de la inhumanidad y nuestra respucsta (Los muertos en el sótano del occidente)", Pasos 67, 1996, pp. 24-30.

6. Considero que no deben faltar para hacerse una idea de conjunto José Comblin, José I. González Faus, Jon Sobrino, Cambio social y pensamiento cristiano en América Latina; Juan José Tamayo, Presente y futuro de la teologla de la liberación,Madrid, 1994; José Comblin, Cristionos rumbo al siglo $\mathrm{XXI}$ (nuevo camino de liberación), Madrid, 1997; el monográfico "Pasión de Dios por la realidad (la teología de la liberación de hoy)", Sal Terrae 83, 1995/9; el también monográfico "¿Qué queda de la teologfa de la liberación?", Exodo 38, 1997; P. Richard, "La teología de la liberación en la nueva coyuntura: temas y desalíos nuevos para la década de los 90 ", Pasos 34, 1991, pp. 1-8; A. Pérez, "Sobre la teología de la liberación", Razón y Fe 226, 1992, pp. 297-310; P. Richard, "El sur existe y tiene su tcología", Envio 137, 1993, pp. 28-41; H. Assmann, "Teología de la liberación: mirando hacia el frente", Pasos 55, 1994, pp. 1-9; J. Sobrino, "La teología y el principio liberación", Revisto Latinoamericana de Teología 35, 1995, pp. 115-140; V. Codina, "La fc del pueblo pobre", ibid, pp. 203-221; F. Hinkelammert, "La metafísica de la inhumanidad y nuestra respuesta", op. cir.; D. Irarrázaval, "Nuevas rutas de la teología latinoamericana", Revisfa Latinoamericana de Teologia 38, 1996, pp. 183-197; F. Chamberlain, “Qué 
que la teología de la liberación, si bien es cierto que no es un enfermo moribundo, tampoco predomina en ella la actilud para quien los cambios de esta década no son tan incisivos como para decir que "aquí no ha ocurrido nada"7. Su estado actual, en mi opinión, puede calificarse y sintetizarse como de renovación.

Una renovación en cuyo dinamismo interior ha distinguido con agudeza $\mathrm{H}$. Assmann tres niveles8: (a) lo que de verdad es irrenunciable, como por ejemplo, la relación entre Dios y los pobres; el lugar de la historia para la revelación divina y la respuesta creyente a ella; la teología como un saber que brota y conduce a la andadura espiritual, etc.; (b) lo que requiere matización, precisión y modificación. como por ejemplo, el lugar de lo político en los procesos de liberación; la vinculación y distinción entre lo individual y lo comunitario, en la recepción y respuesla a la salvación; los pobres son más que una realidad socioeconómica, reflejan todo un mundo y una manera propia de creer, reír, trabajar, etc; el carácter eclesial y tradicional de la teología de la liberación, etc.; (c) y los nuevos temas y enfoques a los que hay que abrirse, tales como los diversos lipos de opresión: cultural, de género, élnica, generacional, etc.; el grave y urgente problema ecológico; las mediaciones nuevas para la liberación, que demanda la mundialización de los vínculos sociales actuales; mejor manejo de los conocimientos exegéticos, históricos y sisternálicos; el diálogo interreligioso; la potenciación de un ecumenismo de la humanidad, en torno a la masividad del sufrimiento, etc.

El estado actual es de renovación. J. Sobrino ha indicado que esta renovación es necesaria y posible, partiendo de la intuición fundamental que dio origen a la teología de la liberación: "hacer central seria y consecuentemente, la relación entre Dios y víctimas de este mundo"9. Tal y como esa relación ha ocurido en Jesucristo, todo lo demás resulta revisable y ampliable, a modo de desafíos y tareas. Como es obvio, lo que queda por hacer -y se está haciendo- no es poco. Aquí, me preguntaré si la dinámica de renovación está afectando a la misma inluición fundamental, y si, de estar incidiendo en ella, a qué nivel. Mi hipótesis es que sí. Que la propia experiencia fundamental está siendo afectada en positivo. Se está dando una especie de retomo crítico a ella, destacando elementos presentes desde el inicio, pero quizá poco subrayados anteriormente; y se está afinando la formulación y conceptualización de la misma experiencia originaria. Veámoslo.

queda por hacer en la perspectiva de la teología de la liberación?", Páginas 142, 1996, pp. 74-83: G. Gutiértez, "El futuro de la reflexión teológica en América Latina", op. cil., pp. 99-165: M. Maier, "Teología de la liberación en Latinoamérica", Razón y Fe 236, 1997, pp. 281-296.

7. J. l. González Faus, "Una tarea histórica: de la liberación a la apocalíplica". Sal Terrae 83/9, 1995. p. 717.

8. Los pocos ejemplos que presento en cada nivel son míos. En algunos casos coincidentes con Assmann.

9. J. Sobrino. "¿Qué queda de la teología de la liberación?", op. cit., p. 49.

Digitalizado por Biblioteca "P. Florentino Idoate, S.J."

Universidad Centroamericana José Simeón Cañas 


\section{2. "Para la libertad nos liberó Cristo..." (Gál 5, 1)}

El punto de partida o experiencia originaria de la teología de la liberación sigue siendo la misma: el advenimiento salvífico del Dios trino al mundo, a través de la realidad de los pobres. La andadura espiritual, que se eleva a perspectiva leologica y que funciona como criterio pastoral en la teología de la liberación, tiene como ráz y savia nutricia el que el mundo de los pobres nos evidencia y acerca el carácter salvífico de Dios en Cristo por su Espíritu.

La novedad en el retomo crítico a la intuición fundamental no está en precisarla, recordarla e incluso en mostrar su validez actual en cuanto la "opresión", correlato trascendental de la liberación, sigue definiendo fundamentalmente nuestra figura sociocultural. La novedad habría que situarla en subrayar el carácter gratuito de la salvación que Dios ofrece a los hombres, cuando se pone en relación indisoluble el advenimiento de ese Dios con las víctimas de este mundo. Para decirlo acudiendo a terminología paulina: en la teología de la liberación se está profundizando lo que significa el que ya "no están bajo la ley, sino bajo la gracia" (Rom 6, 14). La "irrupción de los pobres", que la teología de la liberación ha señalado hasta la saciedad como el gran signo de la presencia interpeladora de Dios en las últimas décadas, se entiende como la señal, en efecto, de que, en Cristo, nuestro tiempo ya no está ni debería estar regido por la ley, sino por la bondad incondicionada e inmerecida de Dios.

Notemos que el subrayado es el carácler gratuito de la salvación. La teología de la liberación mantiene, en este sentido, el ser una teología elaborada en clave y preocupación mesiánica. El cardenal Ratzinger ha señalado que el mayor acierto de este movimiento teológico ha sido el proponer "una respuesla nueva, plausible y, a la vez, práctica, a la cuestión fundamental del cristianismo: el problema de la redención"10. Desde sus inicios hasta hoy, la teología de la liberación intenta pensar y formular todo lo referido a Dios, a Cristo y a su Iglesia, partiendo de la pregunta que lanza el mundo de los pobres al cristianismo: ¿es o no su corazón, el eje en tomo al cual se articulan sus diversos contenidos y significados, el misterio de la salvación? ¿Es o no la salvación acaecida y manifestada en Jesucristo lo que permite asumir cada presente como un kairós, asomarnos al futuro sin temor y recuperar el pasado no como peso que arrastramos, sino como aventurada historia generadora de agradecimiento? En definitiva, la teología de la liberación mantiene su deseo de "ser una teología 'evangéli$\mathrm{ca}^{\prime}$, que ofrece la buena noticia de Dios, redescubierta en el mundo de los pobres, ofrecida directamente a ellos y, a través de ellos, a todos para que haya liberación y humanización" 11 .

10. J. Ratzinger, "Situación actual de la fe y la teología l", op. cir., p. 6.

11. J. Sobrino, "¿Qué queda de la teología de la liberación?”, op. cit., p. 53.

Digitalizado por Biblioteca "P. Florentino Idoate, S.J."

Universidad Centroamericana José Simeón Cañas 
La clave mesiánica se mantiene. El subrayado es lo nuevo: la gratuidad del amor de Dios, evidenciada en su ser buena noticia para los hombres, a través de los pobres, y la asunción de esa gratuidad al optar por ellos para la transformación radical del mundo. Con este subrayado, pocas dudas pueden quedar ya de que no se prefiere a los pobres porque sean mejores personas que otras, o porque sean más abiertos a la prédica religiosa, sino por asemejarse a Dios mismo (Mt 5, 48), quien es amor compasivo, lleno de temura hacia los necesitados de ella, los débiles (Lc 6, 36; 4, 16-21). El vínculo entre gratuidad y pobreza es teologal. No se establece en razón de otros motivos, seguramente muy legítimos, como pueden ser la misericordia humana, la indignación ética que suscita ver tanta miseria e injusticias pulular a nuestro alrededor, o bien por la contundencia con que el análisis social pueda mostrar que en nuestra actitud ante la pobreza de millones de seres humanos nos podemos estar jugando el futuro de la misma humanidad y del medio ambiente. Todo ello, repito, es legítimo y necesario. Pero, para los cristianos, el vínculo es más hondo, es un nexo teologal. Como dice Gutiérrez respecto de la opción preferencial por los pobres: "En la raíz de esa opción está la gratuidad del amor de Dios. Este es el fundamento último de la preferencia [...] Es una opción teocéntrica y profética que hunde sus raíces en la gratuidad del amor de Dios y es requerida por ella"12.

Se podría reaccionar diciendo que la graluidad de la salvación, manifestada en la opción de Dios por los pobres y en la preferencia eclesial por ellos, siernpre ha estado presente y afimada por la teología de la liberación. Es cierto. Pero no lo es menos que, al menos en la predicación, la catequesis y mucha de la literatura teológica de difusión más popular (que son las que suelen incidir más en las convicciones compartidas y que generan el ambiente que se respira) ha predominado un discurso que enfatiza el "compromiso" y la responsabilidad en que nos sumerge la fe, en la buena noticia de Dios, y no tanto la gratuidad de su oferta y su acontecer. Y, sobre todo, si bien es cierlo que siempre se ha caracterizado como gratuita la iniciativa de la salvación divina, en la actualidad, se está mostrando que el carácter gratuito se extiende aún más, que atraviesa al acontecer salvífico mismo. El proceso de liberación es un proceso de agraciamiento, de constitución de la libertad de los hijos de Dios. La leología de la liberación se inscribe, en este sentido, en una teología de la libertad presente en el Nuevo Testamento, en la tradición y en la enseñanza de la Iglesia13. Para ella, la gracia deviene como libertad, se prolonga y se traduce en nuestras magnitudes espaciotemporales, a través de ella. Es la gracia la que constituye la liberad: "En el tiempo se dan cita dos libertades. La libertad de Dios que se revela en la gratuidad de su amor y la liberlad humana que acoge ese don, la primera llama y

12. G. Gutiérrez, "Una teología de la liberación en el contexto del tercer milenio", pp. 111-112 (El subrayado es suyo).

13. Cfr. J. Comblin, "Cristianos numbo al siglo XXI", pp. 63-138.

Digitalizado por Biblioteca "P. Florentino Idoate, S.J."

Universidad Centroamericana José Simeón Cañas 
constituye la segunda"14. ¿Cómo la constituye? La desgaja, creadoramente, sosteniéndola, posibilitándola y olorgándole dirección y sentido. Este proceso activo y permanente de Dios de constitución de nuestra libertad es quizá uno de los campos actuales de reflexión, a lo interno de la teología de la liberación, más novedoso y potente 15 .

La gracia, la bondad incondicionada de Dios, hace brotar la libertad del hombre al desvelar y desatarlo del esquema de la ley en que tiende a situarse (Rom 8, 2), que lo lleva a pecar y que provoca su muerte. La ley no sólo es tomada como un conjunto de prescripciones y normativas que cohesionaba al pueblo judío, sino como un esquema de articulación interna de nuestra manera de vivir, de estar en el mundo, de ver las cosas, de sentir los acontecimientos, de valorar los sucesos y las diversas realidades, de soñar, de padecer y esperar, en el cual queda siempre un resquicio para la autosuficiencia humana ante Dios y ante los hombres. Ante Dios, al pretender que mediante nuestra manera de vivir nos hacemos merecedores de su presencia y su favor. Frente a los hombres, al establecer con ellos unos vínculos anclados en la labilidad del esquema de reciprocidad. Vínculos en los que sólo participarían aquellos que sean capaces de tener "algo" (por lo menos su capacidad de (rabajo) que intercambiar de modo que, los que carecen de ese "algo" en su tener, no se estiman como valiosos en su mismo ser, por lo cual ese ser sobra, está de más. No se formulará, probablemente, con esta crueldad y cinismo, pero se asume y se lleva a cabo prácticamente esta "lógica" del discurso de la ley. Para adentrarnos en su malicia interior basta con que nos detengamos a ver y reflexionar cómo la comprensión neoliberal del mercado está afectando todos los ámbitos de nuestra vidal6, enfrentando en un duelo a muerte la libertad proclamada por san Pablo con la pseudolibertad neoliberal 17.

En Jesucristo y su "referencia vital" al mundo de los pobres 18 , esa identificación entre ser y lener se rompe. Se asienta el dinamismo inevitable, hasta cierto punto, de la reciprocidad en las relaciones, sobre un nuevo "principio", el de la gratuidad, de la pura donación, del amor como ágape. Aquí radica y así opera la novedad mesiánica de Jesucristo19. En El, esa nueva manera de volcarnos a los otros se hace posible porque, a su vez y en la misma medida, la relación para

14. G. Gutiérrez, "Una teología de la liberación en el contexto de América Latina", pp. 100-101.

15. Cfr. A. González, "Trinidad y liberación", San Salvador, pp. 49-82; id., "La vigencia del 'método teológico' de la teología de la liberación". Sal Terrae 83/9, 1995, pp. 667-675.

16. Cfr. H. Assmann, "Las falacias religiosas del mercado", Cristianisme i Justícia 76. 1997. $31 \mathrm{pp}$.

17. Cfr. E. Támez. “Libenad neoliberal y liberıd paulina". Pasos 70. 1997, pp. 11-16.

18. Cfr. J. Sobrino, "Jesús y pobres. Lo mela-paradigmático de las cristologías", Misiones Extranjeras 161, 1997, pp. 499-511.

19. Cfr. X. Pikaza, “Amor 'versus' Ley. Novedad mesiánica de Jesús", Biblia y Fe XX/ 60. 1994, pp. 92-131.

Digitalizado por Biblioteca "P. Florentino Idoate, S.J."

Universidad Centroamericana José Simeón Cañas 
con Dios ha cambiado de signo. En Cristo es Dios quien ha venido a nosotros, quien nos ha asumido libremente, haciendo brotamos y proyectamos como libertad, como transidos de un nuevo paradigma. Ya no el "paradigma del interés propio"20, sino el paradigma de la "apertura al don de sî"2l. La teología de la liberación destaca que cuando adquiere mayor y más diáfana claridad la novedad en que Jesucristo consiste de cara a Dios y a los hombres, la novedad de su gracia es a la luz de su identificación con el mundo de la debilidad y la postración (Mt 25, 31-46).

Se generan miserables y excluidos al mismo tiempo que se es idolátrico, al seguir anclados en la ley, y no en la gracia que es Jesucristo. Es éste quien, identificándose con los miserables, ha roto con ese esquema de existencia, presente no sólo en el pueblo judío de entonces, sino en lodos los pueblos, de ayer y de boy, en las diversas religiones y personas, que acuden a él para su articulación interior y proyección extema. En Jesucristo hemos sido liberados de ese esquema, y se nos ofrece.

El como nuevo "esquema", nuevo "principio personal" de vida, el esquema de la fe inaugurada y propiciada por El22. La liberación que ha realizado respecto de la ley es una liberación a recibir, a acoger, a hacer nuestra. Nos ha situado en un estado de libertad a defender y cultivar, en pugna contra el pecado. La liberación del esquema de la ley se traduce y se expresa en la liberación del pecado, de la ruptura de la amistad con Dios (ruplura que es difícil que sea neutral; suele ser idolátrica); de la ruptura de la fratemidad (injusticia); y de la ruptura de la interacción respetuosa y debida con la naturaleza (depredación). La teología de la liberación insiste en que la liberación integral (económica, social, política, cultural, personal) es propiamente cristiana al ser liberación del pecado como estado en que nos sitúa y como fuerza que canaliza el esquema de la ley. El agraciamiento de Jesucristo muerto y resucilado vence la fuerza del pecado, nos libera de el, al desatamos de su aguijón, de la ley. Y esa liberación desemboca en la vida como triunfo sobre la muerte. De la muerte teologal y física. El es el camino, la verdad y la vida $(J n 14,6)$.

Tres consideraciones requiere la exposición que hemos realizado hasta aquí de cómo la gracia que es y nos lega Jesucristo identificado con los pobres, libera de la ley. En primer lugar, reconocer que en la teología de la liberación ya era dato adquirido la oposición radical entre gracia y pecado. Para ella, ésta es incluso la oposición existente en la única hisloria de la salvación 23. El nuevo

20. H. Assmann, "Teología de la liberación: mirando hacia cl frente", p. 3.

21. Ibid., p. 6.

22. Cfr. A. González, "La fe de Cristo", Revista Latinoamericana de Teología 28, 1993, pp. 63-74.

23. Cfr. I. Ellacuria, "Historicidad de la salvación cristiana", Revisfa Latinoamericana de Teologia 1, 1984, pp. 5-45; ibid,.., "Historia de la salvación", Revista Latinoamericana de Teología 28, 1993, pp. 3-25.

Digitalizado por Biblioteca "P. Florentino Idoate, S.J."

Universidad Centroamericana José Simeón Cañas 
énfasis y, $\mathrm{o}$ aporte es retrotraer y radicalizar esa oposición al nivel más inmediato, la que se da entre la ley y la gracia. Este nivel más primigenio de la oposición está algo diluido en su fuerza interior y en su importante significado para la salvación comprendida como liberación, en un artículo tan profundo y emblemático de la teología de la liberación como es el publicado por I. Ellacuría en 1989, poco antes de su asesinato y en el que precisamente inserta a la teología de la liberación en una teología paulina de la libertad24. Incluso en el penetrante y prospectivo escrito de $G$. Gutiérrez sobre la teología de la liberación de cara al próximo milenio se pasa con demasiada rapidez sobre ese nivel más radical de la oposición. Y curiosamente, en el momento en que también él incorpora a la teología de la liberación en la proclamación de san Pablo sobre la libertad que se nos da en Jesucristo25. Estos dos ejemplos muestran que, aunque se va abriendo paso el nuevo énfasis, no deja de costar retener la mirada y la mente sobre la oposición entre la ley y la gracia, desde la luz que ofrecen las víctimas de la historia.

En segundo lugar, habría que decir que así como el mundo de los pobres dice en directo que la salvación de Dios es plenamente gratuita, el carácter gratuito de dicha salvación ha venido aclarando que "pobres" es una categoría formalmente teológica. No se opone a su contenido socioeconómico e incluso a su comprensión sociocultural. Pero sí que la teología de la liberación se ha venido haciendo cargo y afinando el significado propiamente bíblico y teológico de ese conceplo26, de modo que por pobres habría que entender no tanto un determinado grupo social cuanto aquellos millones de seres humanos considerados como "insignificantes"27, que son a un mismo tiempo excluidos por los hombres y tomados como abandonados por Dios, indignos de El y su amor. Así, Schillebeeckx dirá que la identificación de Jesucristo con los miserables de su liempo posee como significado más profundo el que "arranca a los pobres del desprecio de sí mismos por haber sido discriminados; les devuelve su dignidad de hombres, hijos de Dios"28.

Una tercera y última consideración sería indicar que este nuevo énfasis en la gratuidad del acontecer salvífico no diluye o suaviza su exigencia interior para

24. Cfr. I. Ellacuría, "En lorno al concepto y a la idea de liberación", en Varios, Implicaciones sociales y politicas de la teología de la liberacion, Madrid, 1989, pp. 91-109.

25. Cfr. G. Gutiérrez "Una teología de la liberación en el contexto del tercer milenio", op. cif., pp. 143-146.

26. Cfr. P. Richard, I. Ellacuría, "Pobreza-Pobres", en Conceptos fundamentales del cristianismo, Madrid, 1993, pp. 1030-1057.

27. Cfr. G. Gutiérrez, "Pobres y opción fundamental", en Mysterium liberationis l, Madrid, 1990, pp. 303-323; ibid., "Renovar la opción por los pobres", Sal terrae 83/9, 1995, pp. 677-690; ibid., "Una teologia de la liberación en el contexto del tercer milenio", pp. 127-134; J. Comblin, "Cristianos numbo al siglo XXI", pp. 159-180.

28. E. Schillebeeckx, Los hombres, relato de Dios, Salamanca, 1996, p. 182.

Digitalizado por Biblioteca "P. Florentino Idoate, S.J."

Universidad Centroamericana José Simeón Cañas 
quienes reciben la salvación. No se acude a la gratuidad para compensar el reclamo a la conversión que Dios nos hace, a través de los insignificantes. G. Gutiérrez sale al paso de esta crítica diciendo que "no hay nada más exigente, lo sabemos, que la gratuidad (cfr. la carta de Pablo a Filemón)"29. En la teología de la liberación, en virtud del caminar espiritual y eclesial que le subyace, se "sabe", se ha adquirido conocimiento por propia experiencia que es difícil encontrar algo más exigente que la gratuidad, pues ésta alteró y continúa alterando numerosas vidas, posesionándose de ellas hasta llevarlas al martirio30 y el desgaste. Vidas que el dinamismo de la gratuidad hace suyas, haciéndola transparentar en sus personas y canalizar, mediante sus múltiples actividades y relaciones, un nuevo ethos, el ethos propiamente cristiano. No un conjunto de normas morales, ni siquiera un nuevo y apremiante sentido de la responsabilidad ante los demás, sino una estimación agradecida y apasionada de ser por los demás, con ellos y para ellos. Estimación en pugna terrible con el ethos actual y predominante ${ }^{31}$ para el que no todos valemos lo mismo, y existen millares que ni siquiera entran en el marco de valoración. La oposición frontal a este ethos torna peligrosa, descalificable y fuera de sitio culturalmente, poco gratificante, y demandante de mucha creatividad y fidelidad la acción de la gracia en nosotros. ¿¿Puede parecerle poco exigente a alguno?!

\section{Corriendo hacia Cristo Jesús que nos alcanzó (Flp 3, 12)}

C. Bravo ha mostrado cómo en la teología de la liberación la comprensión de la experiencia originaria que está en su génesis ha transitado del modelo del "éxodo", para dar cuenta de ella, al modelo del "seguimiento de Jesús"32. Esta transición posee más enjundia de lo que a primera vista parece.

Como es sabido, la teología de la liberación se comprendió a sí misma como una "reflexión crítica de la praxis histórica a la luz de la Palabra"33. En los dos términos claves de esa definición, praxis y Palabra, se ha dado una profundización. La "praxis" es un término genérico, que pretende indicar el "puesto en camino", la "búsqueda tras". Toda la persona inmersa en una dinámica activa de recepción, ejercicio y pincelación de su identidad. Dicho así, no se ve por qué es importante esta actual comprensión y amplitud del término. Se percibe su im-

29. G. Gutiérrez, "Una teología de la liberación en el contexto del tercer milenio", op.cit. p. 112.

30. Cfr. J. Sobrino. "De una teología sólo de la liberación a una teología del martirio", en Varios, Cambio social y pensamiento cristiano en América Latina, pp. 101-121: ibid.. "Los mártires y la teología de la liberación", Sal Terrae 83/9, 1995, pp. 699. 715.

31. Cfr. J. Comblin, "La ética que desaparece y la nueva élica que vendrá", Envio 181. 1997, pp. 42-48.

32. Cfr. C. Bravo. "Del tema del Exodo al seguimiento de Jesús", en Cambio social y pensamienso cristiano en América Latina, pp. 79-100.

33. G. Gutiérrez, Teología de la liberación (perspectivas). Salamanca, 3 1973, p. 38.

Digitalizado por Biblioteca "P. Florentino Idoate, S.J."

Universidad Centroamericana José Simeón Cañas 
portancia al contrastarla con las dos comprensiones más extendidas y predominantes durante años. Se ha solido entender que cuando la teología de la liberación habla de "praxis" está postulando y comprendiendo por tal el compromiso polf́tico Iransformador de estructuras injustas. Más aún, que ese compromiso se lleva adelante, según la comprensión y las categorías marxistas. Aquí está el motivo por el cual se considera - y quizá se desea- que la teología de la liberación está desapareciendo. Al venirse abajo el socialismo del este, prelendidamente legitimado en la comprensión marxista de la vida y la historia, centrada en la "praxis transformadora", la teología de la liberación habría perdido su referente.

Conviene decir que, al momento de los acontecimientos de 1989, la relación de la leología de la liberación con el marxismo, tal como dijo Juan L. Segundo, eran ya prácticamente de gentil cortesía. Lo cual no niega que en sus inicios la teología de la liberación pudiera haber acudido al marxismo como método de análisis social y como estrategia de lucha política; pero sí niega el que haya sido una versión religiosa de él y que haya quedado presa de sus categorías y contaminada de su malicia. Las relaciones de la teología de la liberación con el marxismo fueron complejas, de mutua incidencia y crítica, hasta llegar a un distanciamiento cortés por parte de la teología de la liberación, ya que ni siquicra como método de análisis social le terminaba de ser úti|34. Más aún, la teología de la liberación, centrada en la "praxis histórica", ha ido rompiendo la equivalencia de dicho término con el de "obrar político". Partir de la praxis para la rcllexión teológica y pretender que dicha reflexión la ilumine y potencie, no significa que se parta del compromiso político liberador y que lo que se pretenda sea su realización. La teología de la liberación no es una teología de lo político, porque en cuanto tcología es una palabra sobre Dios, sobre el reino de Dios, gustan de precisar sus representantes. Para la teología de la liberación, lo político, ciertamente, es una dimensión clave de lo histórico, pues en ella se toman decisiones y se llevan adelante proyectos sociales que ponen en juego la vida y la muerte real de los hijos de Dios. Lo políitico no puede quedar al margen del mensaje revelado, ni es indiferente a la presencia salvadora de Dios, que ha hecho suya la historia de los hombres para alzarla hasta EI. Pero esta convicción que la teología de la liberación comparte con el magisterio de la Iglesia de la necesidad y urgencia de que lo político esté transido de ética, de valores de libertad y justicia, no la hace perder de vista que aun aceptando que "todo tiene una connotación política [...] la política no lo es, ni mucho menos, todo"35. Lo político le resulta relevante a la teología de la liberación en cuanto

34. Cfr. I. Ellacuría, "Teologfa de la liberación y marxismo", Revista Latinoamericana de Teología 20, 1990, pp. 109-135; G. Gutiérrez, "Teología y ciencias sociales", La verdad os hará libres, Salamanca, 1990, pp. 69-10।.

35. I. Ellacuría, "Aporte de la teología de la liberación a las religiones abrahámicas en la superación del individualismo y del positivismo", Revista Latinoamericana de Teología 10,1987, p. 18.

Digitalizado por Biblioteca "P. Florentino Idoate, S.J."

Universidad Centroamericana José Simeón Cañas 
forma parte de lo histórico, y lo histórico en cuanto es manifestador de lo teologal, de la presencia de Dios en ello.

No es, por tanto, la teología de la liberación una sociología o una politología, sino un modo de saber específico, cuyas fuentes o principios son la revelación, la tradición y el magisterio, a cuyo servicio se ponen ciertas mediaciones. Si entre estas mediaciones tiene cierta importancia la de las ciencias socio-económicas-históricas-políticas no implica necesariamente que se transforme en una de estas ciencias con lenguaje teológico, así como la preferencia clásica por la mediación de la filosofía no hacía necesariamente de la teología anterior una forma de filosofía. En la intención, en la metodología, en los hechos, la teología de la liberación se muestra cada vez más como una teología36.

Esta relativización progresiva del compromiso y obrar político que se ha dado en la teología de la liberación es importante destacarla, porque aún hay quienes se empeñan en considerarla desde allí. Y la hemos expuesto de la mano de I. Ellacuría, porque este pensador, como bien se ha dicho, "era el teólogo de la liberación con mayor sentido de la necesidad, dificultades y ambivalencias de la práctica política en orden a liberar a los oprimidos"37. Según lo anterior, entonces, la "praxis histórica" no debería equipararse más, aunque se haya dado pie para ello, al obrar político transformador de las estructuras sociales. Tampoco - y llegamos a la segunda comprensión - se debe entender por esa praxis la responsabilidad moral. Más arriba nos hemos referido a este punto, por lo que basta aqu con mencionarlo. La teología de la liberación, que reflexiona críticamente la "praxis", no comprende esa praxis en términos primariamente morales. Su afán por la juslicia no responde a un empeño por moralizar las relaciones de los hombres con Dios y entre ellos mismos. Toma como punto de partida la acción humana, en cuanto en ésta se evidencia o puede evidenciarse la asunción fáctica, la confesionalidad creyente en Dios, no con palabras formuladas, sino con la entrega existencial. Para la teología de la liberación la acción es

receptora y, por lo tanto, portadora de "toda la positividad de la fe". Como "lugar teológico". La fe está en la praxis con estatuto de Palabra de Dios o verdad realizada o hecha, en el sentido más fuerte de la expresión: fe como ser o estatuto de "hecha", no de "representada"38.

Hablar de "praxis" en la teología de la liberación no es, pues, un asunto político ni moral. Es asunto teologal. Se parte de la fe realizada, de la Palabra de

36. 1. Ellacurra, "La teología de la liberación frente al cambio socio-histórico de América Latina", Revista Latinoamericana de Teología 12, 1987, p. 242.

37. J. A. Gimbernat, C. Gómez, La pasión por la liberiad (Homenaje a Ignacio Ellacuría), Estella, 1994, p. 8.

38. A. Pérez, "Sobre la leologla de la liberación", pp.cit., p. 303 (los subrayados son suyos). 
Dios recibida y portada. Nos sale así al paso el segundo término clave de la autocomprensión de la teología de la liberación: la Palabra. Lo que se recibe y se porta es la Palabra de Dios. La Palabra definitiva que es Cristo (Heb 1, 1-4), a la luz del cual toda otra palabra divina, anterior (como la expresada en el éxodo) o posterior a El (los llamados signos de los tiempos) adquiere su lugar y verdadero sentido. Hacia esta vivencia y comprensión ha desembocado la teología de la liberación, tal como sugiere C. Bravo. Hagamos, nuevamente, unas cuantas consideraciones.

En primer lugar, esa "praxis" que recibe y porta la palabra divina debe 10marse más como una "forma de vida" en la que se expresa, se ejerce y se concreta la ansiada búsqueda humana de identidad, que como quehacer moral y, o obrar político. Por eso, H. Assmann señala que "el origen de lo que osamos hablar está en los mil ingredientes de los gestos, en lo que llamamos praxis. Sólo allí se descubre que los horizontes tienen piel y que vale la pena acariciar esperanzas" 39 . Praxis, como conjunto y articulación de los gestos, que tejen la condición humana, como "vida en el seguimiento", según la exposición que hace González Faus precisamente de cómo ha evolucionado el concepto de praxis en la teología de G. Gutiérrez ${ }^{40}$. En mi opinión, conviene reconocer que aún no resulta del todo claro y preciso lo que se entiende por "praxis" en la teología de la liberación. También habría que ver si el término mismo resiste el que se le alribuya ese nuevo contenido más amplio y primigenio, según su capacidad evocadora de la experiencia que se desea mostrar y provocar. Consta que alguno de los pensadores que se mueven en la esfera de la teología de la liberación se ha embarcado de manera penetrante y prometedora en el análisis de la densidad filosófica del concepto4l, y esperemos que igualmente nos exponga su idoneidad ya sugerida 42 de cara a la reflexión teológica. Por el momento, no es poca ganancia haber descargado a la "praxis" del reduccionismo moral o político y situarla en la línea del término bíblico de "seguimiento".

Del "seguimiento de Jesucristo" que es, para los cristianos, la Palabra definitiva del Dios vivo. He aquí la segunda consideración. La teología de la liberación ha transitado, cada vez con más diafanidad en su autocomprensión, a ser una teología del seguimiento de Cristo. La Palabra que se recibe, que se acoge y que se porta es Cristo mismo, su persona y su causa (la soberanía de Dios). La intuición fundamental de la teología de la liberación brota del encuentro con

39. H. Assmann. "Teología de la liberación: mirando hacia el frente", p. 5.

40. Cfr. la presentación que hace I. González Faus del libro de J. Martínez Gordo, La fuerza de la debilidad. La teología fundamenial de Gustavo Gutiérrez, Bilbao, 1994. pp. $18-19$.

41. Cfr. A. González. Esıructuras de la praxis (Ensayo de una filosofia primera), Madrid. 1997.

42. Ibid., "El significado filos6́fico de la teología de la liberación", Cambio social y pensamienso cristiano en América Latina, pp. 145-160.

Digitalizado por Biblioteca "P. Florentino Idoate, S.J."

Universidad Centroamericana José Simeón Cañas 
Cristo vivo. Es en ese encuentro con Jesucristo crucificado y resucitado donde aparece la relación del Dios trino con las víctimas de este mundo como una relación indisoluble para la definición misma del Dios cristiano, y para la clarificación de la buena noticia que ha traído a los hombres. Seguir a Cristo, acoger su persona y corresponder a su voluntad, a su sueño sobre este mundo, es lo que testifica la acción de su Espíritu en nosotros, el estar siendo conducidos por la Verdad. La verdad de quién y cómo es Dios, y la verdad en que los hombres consistimos. La verdad de nuestra salvación, de que gracias a la labor del Espíritu estamos siendo "cristificados", pincelados como otros cristos, tallados a su imagen (Rom 8, 29), reproductores de su rostro. Una dinámica en triple vertiente: incorporados al Otro, que es el Padre, siendo conducidos hacia El hasta que lo veamos cara a cara; integrándonos y convirtiéndonos en integradores de los otros, en un mundo donde la desintegración y la exclusión están a la orden del día; y vertidos a lo otro, que es la naturaleza, en un trato respetuoso, de manera que ella pueda, a través de nosotros, ser también liberada y cantar la gloria de Dios.

Es, pues, Cristo la Palabra que ilumina y dirime si nuestra forma de vida testifica o no fe en Dios. Y alimenta el que pueda serlo. El Es la Palabra que se recibe y se porta. Conectemos esta tercera consideración con la idea central del primer apartado de este escrilo. A Jesucristo, que es la gracia que ha superado la ley, se trata de recibirlo y de corresponderle. Recibirlo: podemos ir tras El, porque El nos ha alcanzado previamente, porque ha venido a nosolros con libertad y gerososa gratuidad. Ni la iniciativa, ni su proyecto para el mundo creado, ni la manera adecuada de tratar con su persona y de pelear ese proyecto son obra nuestra, ni resultado de nuestro empeño. Y también portorlo: transparentando su persona en la unidad, riqueza y debilidad de lo que somos, y bregando por significar su sueño, en todos los ámbilos de la existencia de los hombres: a nivel económico, social, cultural, político, etc. La Palabra recibida y portada por la acción del Espíritu, nos agracia, configura en nosotros la ortodoxia (el pensar verdadero), la ortopraxis (el recto obrar) y el ortopathos (el correcto sentir) que, a una, nos expresan y actualizan como hijos de Dios y miembros de su Iglesia.

Finalicemos este apartado indicando que, en virtud de que éste ha sido, básicamente, a mi modo de ver, el derrotero seguido por la teología de la liberación, en su comprensión de la experiencia fundamental que está en su origen y que la mantiene aún viva, recientemente J. Sobrino ha definido a la teología de la liberación como intellectus gratiae. La teología de la liberación, a las puertas del tercer milenio, se autocomprende como una teologia del agraciamiento de Dios, como una teología "posibilitada por lo que es 'otro' y 'buena noticia', el evangelio, Dios y su Cristo Jesús, y los pobres, sus testigos..."43.

43. J. Sobrino, “¿Qué queda de la teología de la liberación?”, p. 50.

Digitalizado por Biblioteca "P. Florentino Idoate, S.J."

Universidad Centroamericana José Simeón Cañas 


\section{A modo de conclusión}

Cerremos ya este escrito. Quizá nos hemos alargado demasiado en la respuesta a la pregunta con que lo encabezamos. Formulémosla de nuevo: ¿qué está significando para la teología de la liberación la etapa postsocialista? Podemos contestar con una palabra: renovación. Ni está como enfermo terminal con los días contados, ni se ha hecho de la vista gorda como si nada hubiese pasado o estuviese sucediendo. Al contrario, sigue cumpliendo su tarea eclesial: comprender y decir una palabra sobre Dios, quien en su advenimiento al mundo desde la realidad de las víctimas trae la buena noticia de nuestra liberación, de nuestra salvación. Que esta tarea sea más anónima que antes, debido a la escasa atención que en general le prestan los medios de comunicación social en la actualidad, no significa que no se esté realizando, y que no esté expresándose en nuevas corrientes, en el tratamiento de graves problemáticas antes poco presentes.

Metz se preguntó, en 1992: "¿qué significa después de todo la teología de la liberación dentro del mundo de la teología?"44. Señaló que su significado más profundo y a agradecer se expresa en la pérdida de una doble inocencia: la inocencia sociopolítica que la reflexión teológica ha pretendido para sí y sus productos; y la pérdida de la inocencia sociocultural, el usual y encubierto etnocentrismo de la teología y sus resultados. Podemos emularlo preguntándonos: ¿qué significa, después de todo, la desaparición del socialismo real del este europeo para la teología de la liberación en su intuición fundamental? Este ha sido el punto de nuestro interés particular. Considero que significa la pérdida de una cierta inocencia antropológica, que tendía a hacerse presente en su discurso sobre la libertad. A la luz de la relación de Dios con las víctimas de este mundo, tal como esta relación se ha manifestado en Jesucristo, la libertad no es "conquistable" por los hombres, mediante un proceso integral de liberación. Es, eso sí, "actualizable" (recibirla y corresponder a ella), legítima y urgentemente, mediante caminos y gestos iberadores en su integralidad. La gratuidad del amor de Dios ha creado libertades que, en Cristo, está redimiendo de la ley, del pecado y de la muerte, por la acción, también gratuita, de su Espíritu. La sutil pero existente distinción entre "conquistar" y "actualizar" se ha ido abriendo paso en la teología de la liberación. La puesta en marcha irreversible de ese paso es lo que aquí he querido sucintamente presentar.

44. Cfr. J. B. Metz, “Teología europea y teología de la liberación”, Cambio social y pensamiento cristiano en América Latina, pp. 263-269.

Digitalizado por Biblioteca "P. Florentino Idoate, S.J."

Universidad Centroamericana José Simeón Cañas 